\title{
Design and Application of Portable Pyrolysis Unit to Convert Plastic Waste into Alternative Fuels
}

\author{
Seedahmed A. I. ${ }^{1}$, Salim W. S. ${ }^{2}$ \\ 1,2: Department of Polymer Engineering, College of Engineering \& Technology of Industries, \\ Sudan University of Science and Technology, Sudan.
}

\begin{abstract}
Conversion of plastic waste into oil fuel had drawn the attention of scientists for the removal of waste from environment as well energy recovery. Pyrolsis of plastic waste had become an important technique to produce plastic waste oil as new supply of energy and alternative to fossil fuel. This study aimed to design portable pyrolysis unit for the conversion of plastic waste materials into useful fuel products from local facilities. Different horizontal and vertical vessels from local materials were designed and used to convert plastic waste such as HDPE and PP into the so called plastic oil. The vertical reactor given better performance than the horizontal for producing oil. Yield around 95\% were achieved. A 5-liter portable pyrolysis unit based on vertical reactor was assembled and equipped with a condenser system, temperature control and collection jar. The unit was used to convert different waste into oil and $500 \mathrm{ml}$ of the resulting oil was used as fuel to replace the traditional fuel of a three legged traditional vehicle (Tuk Tuk). Fortunately, Tuk Tuk traveled distance 30\% more than the distance travelled by same amount of traditional fuel. The designed unit is suitable to be used anywhere if water supply is available using either electrical supply or cooker gas. The prototype can be easily scaled to suit end uses.
\end{abstract}

Keyword: plastic waste, reactor design, waste into fuels.

\section{Introduction:}

Plastic waste is one of the most promising resource for fuel because of its high energy of combustion content and due to the increasing availability of waste in local communities. Petroleum and plastics were hydrocarbons that contain the element of carbon and the difference between them is that plastic molecules have longer carbon chains than those in LPG, petrol and diesel fuel.

The existing commercial pyrolysis technologies seldom run alone with gas, tar and char output as end products, most of them are combined with gasification, combustion and smelting; and the combination with gasification produces moderate-calorific-valued fuel gas, it still receives extensive attention in waste-to-energy processes in recent studies (Smith et al., 2001; Li et al., 2007; Yi, 2007; Ohmukai et al., 2008) and will be a competitive choice in the future. But at the same time, all the combined technologies are expensive and may not be affordable in places where the pyrolysis technology is needed in local communities. (Chen et al, 2014)

The reported reactors for MSW pyrolysis include fixed-bed reactors, rotary kilns, fluidized bed reactors and some innovative reactors. In regards to the reaction conditions, most pyrolysis processes have been conducted at atmospheric pressure. Vacuum pyrolysis has only been reported in studies of special wastes such as printed circuit board disposal (Peng et al., 2006; 


\section{$5^{\text {th }}$ International Conference On Applied Research In SCIENCE, TECHNOLOGY \& KNOWLEDGE}

26-28 February, 2021

Amsterdam, Netherlands

Li et al., 2009). Although vacuum pyrolysis is reported to shorten the residence time of volatile products in the high-temperature zone, reducing the secondary decomposition and increasing the heat value of the gas products, achieving vacuum pyrolysis is difficult in practice. Therefore, all pyrolysis processes are preferably based on atmospheric pressure.

\section{Material and methods}

\subsection{Material:}

High density polyethylene (HDPE), Polypropylene (PP), Low density poly ethylene (LDPE), $\mathrm{PP})$. all the plastic materials were shredded before use.

\subsection{Equipment:}

Reactors made from iron with different accessories, gas stove, jar, temperature control, condenser.

\subsection{Methods:}

\subsubsection{Vertical Reactor V1}

5-liter vertical reactor as shown in figure (2.1) was designed and constructed from iron using local facilities. The condensation unit was a jar of water.

Fig.1: Vertical reactor Trial 1

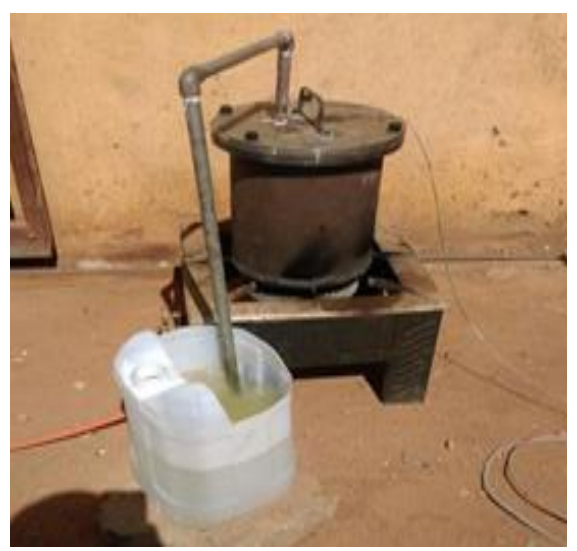

Source: (Salim Seedahmed (2018),A)

$1 \mathrm{~kg}$ of HDPE plastic waste was placed inside the reactor; reactor closed and heated using a cooker heater for 1 hour. Condensed gas into oil in the surface of the water was collected and its volume was measured. This was repeated for PP Figures (2 and 3) show resulted oil. 
Fig.6: HDPE plastic oil

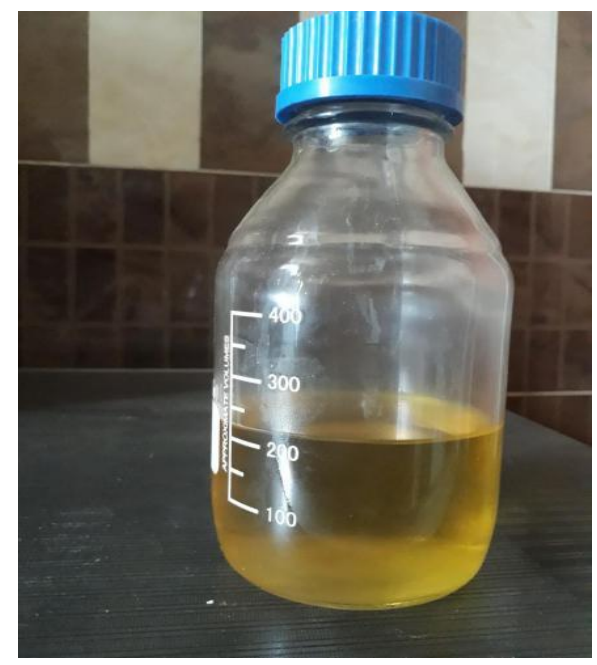

Fig.7: PP plastic oil

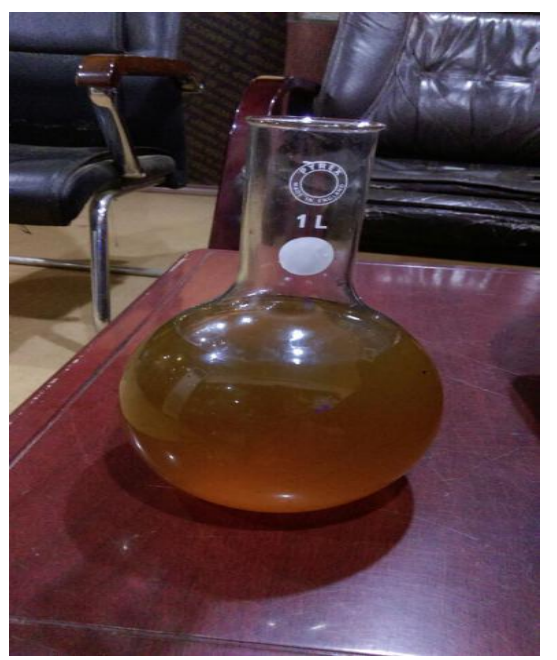

\subsection{Application of Plastic Oil}

$500 \mathrm{ml}$ of plastic fuel (HDPE and PP) and $500 \mathrm{ml}$ of traditional fuel was used separately for Tuk Tuk and the distances travelled were measured in each case.

Fig.8: The traditional TukTuk

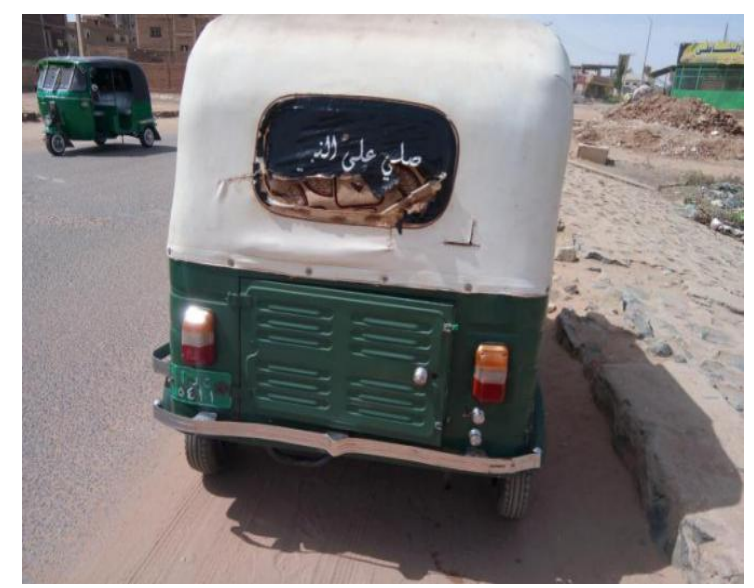

Fig.9: The plastic oil used to fuel TuKTuk

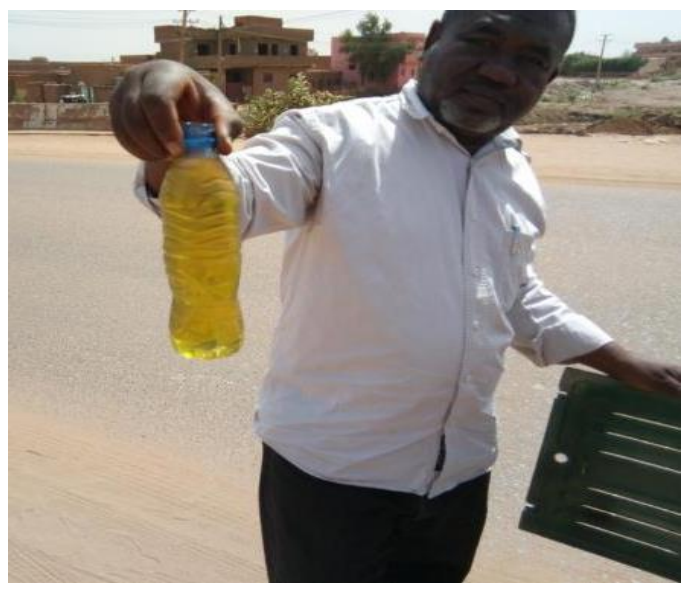

Source: (Salim Seedahmed (2018),B)

\section{Results and Discussions}

Tab.1: Conversion Yield percentages

\begin{tabular}{|c|c|c|}
\hline Material & Reactor & Conversion \\
\hline HDPE & V1 & 81.7 \\
\hline HDPE & V3 & 95 \\
\hline PP & V1 & 82.2 \\
\hline PP & V3 & 92 \\
\hline
\end{tabular}




\section{$5^{\text {th }}$ International Conference On Applied Research In SCIENCE, TECHNOLOGY \& KNOWLEDGE}

26-28 February, 2021

Amsterdam, Netherlands

For instance, it seems the PPU unit gives better performance against the first trail and this is eventually due to the good control of temperature and proper condensation. The PPU unit looks portable which may give an opportunity to process waste anywhere as far as water for condensation and heating media is available

The distance travelled by the $500 \mathrm{ml}$ of HDPE and PP plastic oil when used as fuel to replace the same amount of traditional fuel of tuk tuk. was $13 \mathrm{Km}$ while $10 \mathrm{Km}$ in the case of domestic fuel. This means plastic oil fuel performance is $30 \%$ better the the traditional tuk tuk fuel.

$100 \mathrm{ml}$ of mixed plastic oil (HDPE and PP) where used in a cresset and it gives lighting for 9 hours.

\section{Conclusion}

PPU design is useful and need to be further enhanced to produce alternative fuel for daily life applications like that used by motor TUK TUK or even for burning and lighting

\section{Acknowledgement}

Authors are acknowledged to the Sudanese Ministry of Higher Education and Scientific Research for funding this work.

\section{References}

1. Salim W.S., Seedahmed A.I., (2018), "Application of Waste Plastic Oil as Alternative Fuel”, International Journal of Engineering Research \& Technology 7(7), 105-109

2. Salim W.S., Seedahmed A.I., (2018), "Design and Use of a Reactor to Convert Plastic Waste into Useful Fuel", International Journal of Engineering Research \& Technology 1(7), 251-253.

3. United Nations Environmental Program, (2009) “converting waste plastic into a resource", compendium of technology, Japan.

4. D. Chen, L. Yin and H. Wang, (2012) "A Review Pyrolysis technologies for municipal solid waste", College of Environmental Science and Engineering, Tongji University, Shanghai, China.

5. L. Nageswara, L. Jayanthi and D. Kamalakar "Conversion of waste plastics into alternative fuel "4(8): August, 2015

6. Elfaki E. Ali, Seedahmed A. I., Khaled A. Abuhasel, Abdallah K. Abdallah, (2019), "Design and Utilization of a Pyrolysis Unit to Convert Plastic Waste into Fuels", International Journal of Sciences and Research(PONTE) 25(4/1), 161 -172.

7. Alajail A.I., Seedahmed A. I., Karama B A. and Shaneb O. A., (2014), "A framework for Conversion of Plastic Waste into Fuels and Chemicals: A review of the waste current situation in Libya", Applied Mechanics and Materials, 664, 80 - 86.

8. Garib Alla M. M., Seedahmed A. I., and Karama B A, (2014), "Conversion of Plastics Waste to Liquid Fuel", International Journal of Technical Research and Applications, 2(3), 29-31. 